\title{
Demographic and Clinical Factors Associated with Patient-Reported Remission in Psoriasis
}

\author{
George Gondo · Edward Hadeler · Nicholas Brownstone • \\ Emanual Maverakis · Joseph F. Merola · April W. Armstrong • \\ Tina Bhutani $\cdot$ Stacie J. Bell $\cdot$ Wilson Liao (D)
}

Received: January 12, 2022 / Accepted: February 8, 2022 / Published online: March 7, 2022

(c) The Author(s) 2022

\begin{abstract}
Introduction: Achievement of remission in psoriasis is a key goal for patients and providers, yet definitions of remission may vary. Some treat-to-target initiatives in psoriasis have focused on degree of skin involvement, while others have also incorporated quality of life (QoL) measures. The goal of this study is to identify factors associated with patient-reported psoriasis remission.
\end{abstract}

G. Gondo

National Psoriasis Foundation, Portland, OR, USA

E. Hadeler $\cdot$ N. Brownstone $\cdot$ T. Bhutani .

W. Liao $(\square)$

University of California at San Francisco, San

Francisco, CA, USA

e-mail: wilson.liao@ucsf.edu

\section{E. Maverakis}

University of California at Davis, Sacramento, CA, USA

J. F. Merola

Brigham and Women's Hospital, Harvard Medical School, Boston, MA, USA

A. W. Armstrong

University of Southern California, Los Angeles, CA, USA

S. J. Bell

Opsis Health/Global Nutrition Project, Colorado, USA
Methods: The National Psoriasis Foundation conducted a survey of a random stratified sample of 1570 individuals with psoriatic disease in the USA. The survey contained questions regarding provider diagnosis of psoriasis and/or psoriatic arthritis, as well as comorbid conditions and participant demographics. Psoriasis severity was assessed using the Patient Report of Extent of Psoriasis Involvement (PREPI), a validated self-reported measure of body surface area (BSA). Dermatologic-related quality of life was assessed using the Dermatology Life Quality Index (DLQI). Individuals reporting BSA $\leq 3 \%$ were asked if they believed their psoriasis was in remission. Multivariate logistic regression was used to identify factors associated with remission.

Results: Of 930 participants reporting BSA $\leq 3 \%, 479(51.7 \%)$ believed their psoriasis was in remission, with an average remission duration of 31 months. Of those in remission, 79.1\% reported current treatment. Multivariate regression revealed that psoriasis remission was independently associated with female sex, lower BSA, less impairment in the Dermatology Life Quality Index and global QoL, biologic use, and concomitant diagnosis of psoriatic arthritis. There was no association with age, race, body mass index, or number of comorbidities.

Conclusion: Overall, patient perception of psoriasis remission was not solely associated with BSA, but also with sex, quality of life, and treatment type. 
Keywords: Psoriasis; Psoriatic arthritis; Remission; Treat-to-target; Quality of life

\section{Key Summary Points}

Why carry out this study?

Remission in psoriasis is an important goal for patients and clinical providers.

Compared with provider-defined psoriasis remission, patient-defined psoriasis is not well understood.

This study sought to understand remission from a patient-centered perspective by identifying demographic and clinical factors associated with patient-reported remission of psoriasis.

\section{What was learned from the study?}

Factors beyond body surface area were associated with patient-reported psoriasis remission. Less disease impact on quality of life was associated with patientreported psoriasis remission. Additionally, females and individuals who used a biologic therapy to treat their psoriasis in the last 12 months were also more likely to report their psoriasis in remission.

Clinicians should consider disease impact on quality of life when defining psoriasis remission.

Female sex and biologic therapy use are factors that may increase the likelihood of achieving remission.

\section{INTRODUCTION}

The efficacy of psoriasis treatments has steadily improved over the last two decades [1]. Systemic agents, including biologic agents that target inflammatory cytokines, have emerged as some of the most effective treatment options. As the efficacy of biologic agents has increased, clinical outcome measures for trials have become more stringent. A number of trials have incorporated clinical outcomes such as achieving a body surface area $(\mathrm{BSA}) \leq 1 \%$, and a $90 \%$ or $100 \%$ reduction in Psoriasis Area and Severity Index (PASI90, PASI100) [2, 3].

As clinical outcomes for psoriasis have improved, dermatology organizations around the world have aimed to define successful treatment and remission. In the USA, the National Psoriasis Foundation (NPF) proposed that the target response to treatment is a BSA $\leq 1 \%$ at 3 months after initiating therapy and $\leq 1 \%$ every 6 months during the maintenance period [4]. The Belgian consensus added on the concept of treat-to-target, emphasizing that both disease severity and quality of life measures are essential components of remission, and variables that capture the patient's perspective of their condition should be considered as well [5].

To further explore remission from a patientcentered view, the NPF aimed to identify demographic and clinical factors associated with patient-reported remission of psoriasis.

\section{METHODS}

The National Psoriasis Foundation conducted a cross-sectional study using an online and telephone-based survey of a random, stratified sample of individuals with psoriasis in October and November 2019. The survey was approved by the Genetic Alliance Institutional Review Board. Participants included individuals living in the USA with a physician-given diagnoses of psoriasis and/or psoriatic arthritis, 18 years of age or older, who contacted the foundation between 2017 and 2019. The Patient Report of Extent of Psoriasis Involvement (PREPI) was used to assess severity of psoriasis at the time of data collection [6]. Participants who reported a body surface area (BSA) of $3 \%$ or less were asked questions about their perspective on whether their psoriasis is in remission. Quality of life was assessed using a global quality of life question and the Dermatology Life Quality Index (DLQI). The DLQI is a well-established, validated tool to assess dermatology-specific quality of life $[7,8]$. The global quality of life question asked 
participants the following questions: "[c]onsidering all the ways your psoriasis and/or psoriatic arthritis may affect you at this time, please indicate you are doing" on a scale of 0-10 with 0 being "very well" and 10 being "very poorly." The survey asked participants about their current and past treatments, physician diagnosed comorbidities (see Table 1), and demographics, including race, biological sex, height, and weight. Participant-reported height and weight were used to calculate body mass index (BMI)

Table 1 Comorbidities surveyed

Question: Has a doctor ever told you that you have any of the following conditions?

\begin{tabular}{|c|c|c|}
\hline $\begin{array}{l}\text { Cardiovascular } \\
\text { disease }\end{array}$ & Dyslipidemia & $\begin{array}{l}\text { Chronic } \\
\text { obstructive } \\
\text { pulmonary } \\
\text { disease } \\
\text { (COPD) }\end{array}$ \\
\hline Stroke & Depression & Uveitis \\
\hline Hypertension & Anxiety & Liver disease \\
\hline $\begin{array}{l}\text { High blood } \\
\text { pressure }\end{array}$ & Sexual dysfunction & $\begin{array}{c}\text { Fatty liver } \\
\text { disease }\end{array}$ \\
\hline Heart attack & Crohn's disease & $\begin{array}{l}\text { Rheumatoid } \\
\text { arthritis }\end{array}$ \\
\hline $\begin{array}{c}\text { Adult onset } \\
\text { diabetes } \\
\text { (Type } 2 \\
\text { diabetes) }\end{array}$ & Ulcerative colitis & Gout \\
\hline $\begin{array}{l}\text { Metabolic } \\
\text { syndrome }\end{array}$ & Cancer & Osteoarthritis \\
\hline $\begin{array}{l}\text { High } \\
\text { triglyceride } \\
\text { levels }\end{array}$ & $\begin{array}{l}\text { Cutaneous T-cell } \\
\text { lymphoma }\end{array}$ & Fibromyalgia \\
\hline $\begin{array}{l}\text { High } \\
\text { cholesterol }\end{array}$ & Chronic kidney disease & Thyroid disease \\
\hline $\begin{array}{l}\text { Coronary } \\
\text { artery disease }\end{array}$ & Sleep apnea & Other (specify) \\
\hline Atherosclerosis & $\begin{array}{l}\text { Hardening/narrowing } \\
\text { of arteries }\end{array}$ & $\begin{array}{l}\text { None of the } \\
\text { above }\end{array}$ \\
\hline
\end{tabular}

using the standard formula: weight (lb)/height $(\text { in })^{2} \times 703$

Descriptive statistics were used to report the number and percentage of respondents who believe their psoriasis is in remission. Chisquare tests of independence were conducted to explore characteristics associated with patient perception of psoriasis remission. Characteristics associated with remission were included in logistic regression models used to assess factors related to patient perception of psoriasis remission. For the logistic regression models, the continuous variable for age was used, race was collapsed into a dichotomous "white" and "non-white" variable due to the lack of racial diversity among participants, and a continuous variable for BSA was used for disease severity. The number of comorbidities reported by each participant was created by summing responses to the question about physician-given diagnoses of comorbid conditions (Table 1). Hypertension and high blood pressure were counted as one comorbidity for high blood pressure. Cardiovascular disease, stroke, and heart attack were counted as one comorbidity for cardiovascular disease. Atherosclerosis and narrowing of the arteries were counted as one question for atherosclerosis.

A total of 1570 individuals with psoriasis completed the survey, including 736 (46.9\%) diagnosed by a physician with psoriasis, 76 (4.8\%) diagnosed with psoriatic arthritis, and $758(48.3 \%)$ with psoriasis and psoriatic arthritis. Among individuals with psoriasis, 783 $(49.9 \%)$ reported mild psoriasis (BSA $<3 \%)$ and $787(50.1 \%)$ reported moderate to severe psoriasis (BSA $\geq 3 \%$ ). Individuals diagnosed with psoriatic arthritis without a concomitant diagnosis of psoriasis and individuals with a selfreported $\mathrm{BSA}>3 \%$ at the time of data collection were excluded from the analyses.

\section{RESULTS}

Among the 1570 individuals who completed the survey, $930(63.7 \%)$ reported a BSA $\leq 3 \%$ and were asked if they believed their psoriasis was in remission. Of these, 479 (51.7\%), believed that their psoriasis was in remission 
(Table 3). Participants with psoriasis and a BSA $\leq 3 \%$ were mostly white $(89.4 \%)$, female $(59.1 \%)$, over the age of 50 years $(60.7 \%)$, and were overweight or obese $(68.4 \%)$ (Table 2$)$. Participants with psoriasis only $(470,50.5 \%)$ and psoriasis and psoriatic arthritis (460, 49.5\%) were evenly represented (Table 3 ). Most participants with $\mathrm{BSA} \leq 3 \%$ believed their psoriasis had a small $(314,38.8 \%)$ or no effect $(282$, $34.8 \%)$ on their quality of life, based on DLQI results (Table 3 ).

Table 2 Participant demographics

\begin{tabular}{lc}
\hline Characteristic & $n(\%)$ \\
\hline Race & \\
White or Caucasian & $819(89.4 \%)$ \\
Asian or Asian American & $37(4.0 \%)$ \\
Black or African American & $13(1.4 \%)$ \\
American Indian or Alaskan Native & $9(1.0 \%)$ \\
Native Hawaiian or other Pacific Island & $2(0.2 \%)$ \\
Two or more races & $19(2.1 \%)$ \\
Other & $8(0.9 \%)$ \\
Unsure & $9(1.0 \%)$ \\
Biological sex & \\
Male & $376(40.9 \%)$ \\
Female & $544(59.1 \%)$ \\
Age & \\
18-35 years & $98(11.0 \%)$ \\
$36-50$ years & $254(28.4 \%)$ \\
$51-65$ years & $325(36.3 \%)$ \\
Older than 65 years & $219(24.4 \%)$ \\
BMI categories & \\
Underweight & $260(29.8 \%)$ \\
Normal weight & $298(34.2 \%)$ \\
Overweight & $298(34.2 \%)$ \\
\hline & \\
\hline &
\end{tabular}

Table 3 Descriptive statistics of participants

\begin{tabular}{lc}
\hline Response & $n(\%)$ \\
\hline Disease diagnosed & $470(50.5 \%)$ \\
Psoriasis & $460(49.5 \%)$ \\
Psoriasis and psoriatic arthritis & \\
Disease severity & $123(13.2 \%)$ \\
0\% BSA & $439(47.2 \%)$ \\
$1 \%$ BSA & $221(23.7 \%)$ \\
2\% BSA & $147(15.8 \%)$ \\
$3 \%$ BSA & \\
DLQI interpretation & $282(34.8 \%)$ \\
No effect at all & $314(38.8 \%)$ \\
Small effect & $141(17.4 \%)$ \\
Moderate effect & $67(8.3 \%)$ \\
Very large effect & $6(0.7 \%)$ \\
Extremely large effect & $479(51.7 \%)$ \\
Perception of remission & \\
PsO not in remission & \\
\hline & \\
PsO in remission & \\
\hline
\end{tabular}

Results from chi-square tests of independence suggest that type of disease diagnosed, BSA, biologic use, and DLQI score are related to perception of psoriasis in remission (Table 4). Compared with individuals with psoriasis, only $(43.6 \%)$, a higher percentage of those with psoriasis and psoriatic arthritis (56.4\%), perceived their psoriasis was in remission $(p<0.001)$. The percentage of participants perceiving their psoriasis as in remission increased as BSA decreased. However, among those who perceived their psoriasis as being in remission, only $22.7 \%$ reported having full clear skin and $51.6 \%$ reported having 1\% BSA. A higher percentage of those who perceived their psoriasis was in remission reported using a biologic therapy $(65.2 \%)$ compared with those not using a biologic therapy $(34.8 \%, p<0.001)$. Nearly $14 \%$ of participants who perceived their 
Table 4 Chi-square tests of independence comparing remission status

\begin{tabular}{|c|c|c|}
\hline Response & $\begin{array}{l}\text { Not in } \\
\text { remission }\end{array}$ & $\begin{array}{l}\text { In } \\
\text { remission }\end{array}$ \\
\hline \multicolumn{3}{|l|}{ Disease diagnosed $^{* * *}$} \\
\hline Psoriasis & $258(57.6 \%)$ & $209(43.6 \%)$ \\
\hline $\begin{array}{l}\text { Psoriasis and psoriatic } \\
\text { arthritis }\end{array}$ & $190(42.4 \%)$ & $270(56.4 \%)$ \\
\hline \multicolumn{3}{|l|}{ Disease severity ${ }^{* * *}$} \\
\hline $0 \%$ BSA & $13(2.9 \%)$ & $109(22.7 \%)$ \\
\hline $1 \% \mathrm{BSA}$ & $190(42.4 \%)$ & $247(51.6 \%)$ \\
\hline $2 \% \mathrm{BSA}$ & $143(31.9 \%)$ & $78(16.3 \%)$ \\
\hline $3 \%$ BSA & $102(22.7 \%)$ & $45(9.4 \%)$ \\
\hline \multicolumn{3}{|l|}{ Biologic use $\mathrm{e}^{* * *}$} \\
\hline Not biologic user & $255(59.1 \%)$ & $160(34.8 \%)$ \\
\hline Biologic user & $176(40.9 \%)$ & $300(65.2 \%)$ \\
\hline \multicolumn{3}{|l|}{ DLQI interpretation*** } \\
\hline No effect at all & $60(15.4 \%)$ & $222(52.9 \%)$ \\
\hline Small effect & $174(44.6 \%)$ & $140(33.3 \%)$ \\
\hline Moderate effect & $99(25.4 \%)$ & $42(10.0 \%)$ \\
\hline Very large effect & $53(13.6 \%)$ & $14(3.3 \%)$ \\
\hline Extremely large effect & $4(1.0 \%)$ & $2(.5 \%)$ \\
\hline
\end{tabular}

${ }^{* * *}$ indicates $\mathrm{p}<0.001$

psoriasis was in remission reported their skin disease had a moderate to extremely large effect on their quality of life $(p<0.001)$.

Factors associated with perception of psoriasis remission were explored using logistic regression. Results from multivariate logistic regression suggest that skin specific [OR $=0.87$, 95\% CI (0.82-0.92)] and global quality of life $[\mathrm{OR}=0.80,95 \% \mathrm{CI}(0.72-0.86)]$, BSA $[\mathrm{OR}=$ $0.71,95 \%$ CI $(0.57-0.88)]$, male sex [OR $=0.65$, 95\% CI (0.46-0.94)], biologic use [OR $=2.26$, 95\% CI (1.54-5.51)], and concomitant diagnosis of psoriatic arthritis $[\mathrm{OR}=2.04,95 \%$ CI (1.38-3.02)] are associated with increased likelihood of feeling psoriasis was in remission (Table 5). An increased impact of skin disease on quality of life was associated with a 13\% decrease in likelihood of perceiving psoriasis was in remission. For each decrease in global quality of life, the likelihood of perceiving psoriasis was in remission decreased by $20 \%$. Each percentage of BSA affected by psoriasis decreased perception of psoriasis in remission by $29 \%$. Males were $35 \%$ less likely to perceive their psoriasis as being in remission than females. Using a biologic therapy to treat psoriasis increased the likelihood of perceiving psoriasis was in remission by $126 \%$. Having a concomitant diagnosis of psoriatic arthritis increased the likelihood of perceiving psoriasis was in remission by $104 \%$.

\section{DISCUSSION}

This study highlights several clinical and demographic factors associated with psoriasis remission from the perspective of patients.

Patients were more likely to report remission status in relation to having a lower BSA of psoriasis disease. Interestingly, a significant subset of patients who reported not having clear skin or a BSA of $1 \%$ indicated that they believed they were in remission. A treat-to-target consensus performed by the National Psoriasis Foundation within the USA, published in 2017, established BSA as the most preferred outcome for establishing a treatment target among dermatologists [4]. This study indicates that having completely clear skin or a BSA $\leq 1 \%$, though a very important factor for remission, does not fully correlate with remission status from the perspective of all patients.

Quality of life was another significant factor associated with patient-reported remission. A treat-to-target consensus performed by the Belgian consensus added upon the United States concept of treat-to-target, indicating that quality of life be included within the definition in addition to disease severity measures [5]. The consensus, published in 2020, incorporates clinical severity, quality of life, tolerability of side effects, and comorbidity in their definition for treat-to-target [5]. Quality of life strongly correlates with disease severity, but our study further highlights that quality of life also 
Table 5 Logistic regression models of factors associated with remission status

\begin{tabular}{|c|c|c|c|c|}
\hline & \multicolumn{4}{|c|}{ Psoriasis is in remission } \\
\hline & $\begin{array}{l}\text { Odds } \\
\text { Ratio }\end{array}$ & SE & $96 \% \mathrm{CI}$ & $p$ value \\
\hline \multicolumn{5}{|l|}{ Model 1} \\
\hline DLQI Scale & 0.80 & 0.018 & $0.76-0.84$ & $<0.001$ \\
\hline \multicolumn{5}{|l|}{ Model 2} \\
\hline DLQI Scale & 0.83 & 0.020 & $0.79-0.87$ & $<0.001$ \\
\hline $\begin{array}{l}\text { Global } \\
\text { QoL }\end{array}$ & 0.83 & 0.028 & $0.77-0.89$ & $<0.001$ \\
\hline \multicolumn{5}{|l|}{ Model 3} \\
\hline DLQI Scale & 0.86 & 0.021 & $0.82-0.91$ & $<0.001$ \\
\hline $\begin{array}{l}\text { Global } \\
\text { QoL }\end{array}$ & 0.84 & 0.030 & $0.78-0.90$ & $<0.001$ \\
\hline BSA & 0.56 & 0.055 & $0.46-0.68$ & $<0.001$ \\
\hline \multicolumn{5}{|l|}{ Model 4} \\
\hline DLQI Scale & 0.85 & 0.021 & $0.81-0.90$ & $<0.001$ \\
\hline $\begin{array}{l}\text { Global } \\
\text { QoL }\end{array}$ & 0.83 & 0.030 & $0.77-0.89$ & $<0.001$ \\
\hline BSA & 0.58 & 0.058 & $0.48-0.71$ & $<0.001$ \\
\hline Male & 0.68 & 0.114 & $0.49-0.95$ & 0.023 \\
\hline \multicolumn{5}{|l|}{ Model 5} \\
\hline DLQI Scale & 0.86 & 0.022 & $0.82-0.91$ & $<0.001$ \\
\hline $\begin{array}{l}\text { Global } \\
\text { QoL }\end{array}$ & 0.82 & 0.031 & $0.76-0.88$ & $<0.001$ \\
\hline BSA & 0.65 & 0.068 & $0.53-0.80$ & $<0.001$ \\
\hline Male & 0.67 & 0.115 & $0.47-0.93$ & 0.019 \\
\hline $\begin{array}{l}\text { Biologic } \\
\text { user }\end{array}$ & 2.72 & 0.46 & $1.95-3.79$ & $<0.001$ \\
\hline \multicolumn{5}{|l|}{ Model 6} \\
\hline DLQI Scale & 0.87 & 0.022 & $0.83-0.91$ & $<0.001$ \\
\hline $\begin{array}{l}\text { Global } \\
\text { QoL }\end{array}$ & 0.78 & 0.032 & $0.73-0.85$ & $<0.001$ \\
\hline BSA & 0.65 & 0.069 & $0.53-0.81$ & $<0.001$ \\
\hline Male & 0.68 & 0.118 & $0.48-0.96$ & 0.27 \\
\hline
\end{tabular}

Table 5 continued

\begin{tabular}{llllr}
\hline & \multicolumn{4}{l}{ Psoriasis is in remission } \\
\cline { 2 - 5 } & $\begin{array}{l}\text { Odds } \\
\text { Ratio }\end{array}$ & SE & 96\% CI & $p$ value \\
\hline $\begin{array}{l}\text { Biologic } \\
\text { user }\end{array}$ & 2.19 & 0.398 & $1.53-3.13$ & $<0.001$ \\
Has PsA & 1.88 & 0.358 & $1.29-2.73$ & 0.001 \\
Model 7 & & & & \\
DLQI Scale & 0.87 & 0.023 & $0.82-0.92$ & $<0.001$ \\
Global & 0.80 & 0.033 & $0.72-0.86$ & $<0.001$ \\
QoL & & & & \\
BSA & 0.71 & 0.079 & $0.57-0.88$ & 0.002 \\
Male & 0.65 & 0.121 & $0.46-0.94$ & 0.023 \\
Biologic & 2.26 & 0.439 & $1.54-3.31$ & $<0.001$ \\
user & & & & \\
Has PsA & 2.04 & 0.409 & $1.38-3.02$ & $<0.001$ \\
Age & 1.00 & 0.007 & $0.99-1.01$ & 0.624 \\
White & 0.87 & 0.262 & $0.48-1.57$ & 0.644 \\
Obese & 0.74 & 0.147 & $0.50-1.09$ & 0.129 \\
\hline
\end{tabular}

independently contributes to patients' perception of remission.

Furthermore, biologic use was significantly associated with patients reporting remission. Many biologic agents can improve both joint and skin symptoms with very few serious side effects [1], and this favorable benefit-to-risk ratio may lead to improvements in patient satisfaction and perception of remission.

Our study highlighted some additional interesting factors associated with remission status. Patients who self-identified as male were less likely to report remission, while females were more likely to report remission. A recent study conducted by Murer et al. surveyed 1979 psoriasis patients and compared differences between patient gender and psoriasis symptoms [9]. They found that pruritus was identified as the most significant symptom in relation to 
quality of life and that females reported higher rates of psoriatic pruritus, as well as lower satisfaction with treatment [9]. A study conducted by Mabuchi et al. in Japan also reported that female patients reported worse quality of life scores than men [10]. Moreover, studies have shown that females report higher intensities of experimentally induced itch compared with males and have higher plasma levels of drugs used to treat itch compared with males $[11,12]$. Therefore, it is possible that, compared with males, females may experience more intense psoriasis symptoms and improved treatment responses.

Interestingly, patients who reported a concomitant diagnosis of psoriatic arthritis were also more likely to report remission status. Psoriatic arthritis results in a substantial functional impact on quality of life in patients [13]. In a study evaluating psoriasis patients with skin and joint symptoms, patients prioritized the burden of joint over skin symptoms [14]. Our study may indicate that psoriatic arthritis patients, who have a large combined burden of skin and joint disease, may view improvement in skin or joint symptoms more favorably than those with skin symptoms alone.

\section{CONCLUSION}

Remission in psoriasis is an evolving concept that is actively being developed. Capturing the perspectives of patients on remission will ultimately assist in the shared decision-making process between patients and providers in discussing treatment goals. Using a large national survey, our study identified several factors related to remission in psoriasis. Among surveyed patients, we found that that psoriasis BSA and quality of life were significant factors, which have previously been highlighted in other treatto-target initiatives. New factors including, sex, biologic use, and diagnosis of psoriatic arthritis, were also significant regarding patient-reported remission status. Ultimately, our study provides further evidence that remission may encompass multiple domains.

\section{ACKNOWLEDGMENTS}

Funding. No funding or sponsorship was received for this study or publication of this article.

Medical Writing/Editorial Assistance. None received.

Authorship. All named authors meet the International Committee of Medical Journal Editors (ICMJE) criteria for authorship for this article, take responsibility for the integrity of the work as a whole, and have given their approval for this version to be published.

Author Contributions. George Gondo and Stacie J. Bell collected the data. George Gondo, Edward Hadeler, Nicholas Brownstone, Tina Bhutani, and Wilson Liao performed data analysis. George Gondo, Edward Hadeler, Nicholas Brownstone, Emanual Maverakis, Joseph F. Merola, April W. Armstrong, Tina Bhutani, and Wilson Liao drafted, reviewed, and edited the manuscript.

Disclosures. April W. Armstrong serves as a research investigator and/or scientific advisor to AbbVie, Almirall, Arcutis, ASLAN, BI, BMS, EPI, Incyte, Leo, UCB, Janssen, Lilly, Nimbus, Novartis, Ortho Dermatologics, Sun, Dermavant, Dermira, Sanofi, Regeneron, Pfizer, and Modmed. George Gondo is an employee of the National Psoriasis Foundation and Stacie J. Bell was an employee of the National Psoriasis Foundation at the time of this work. Wilson Liao has received research grant funding from Abbvie, Amgen, Janssen, Leo, Novartis, Pfizer, Regeneron, and TRex Bio. Joseph F. Merola serves as a consultant or investigator for Merck, Abbvie, Dermavant, Eli Lilly, Novartis, Janssen, UCB, Celgene, Sanofi, Regeneron, Arena, Sun Pharma, Biogen, Pfizer, EMD Serono, Avotres, and Leo Pharma. Tina Bhutani is a principal investigator for trials sponsored by Abbvie, Castle, CorEvitas, Dermavant, Galderma, Mindera, and Pfizer. She has received research grant funding from Novartis and Regeneron. She has been an advisor for Abbvie, Arcutis, Boehringer- 
Ingelheim, Bristol Myers Squibb, Janssen, Leo, Lilly, Novartis, Pfizer, Sun, and UCB. Edward Hadeler, Emanual Maverakis, and Nicholas Brownstone state no conflict of interest.

Compliance with Ethics Guidelines. This study was approved by the Genetic Alliance Institutional Review Board.

Data Availability. The datasets generated during and/or analyzed during the current study are available from the corresponding author on reasonable request.

Open Access. This article is licensed under a Creative Commons Attribution-NonCommercial 4.0 International License, which permits any non-commercial use, sharing, adaptation, distribution and reproduction in any medium or format, as long as you give appropriate credit to the original author(s) and the source, provide a link to the Creative Commons licence, and indicate if changes were made. The images or other third party material in this article are included in the article's Creative Commons licence, unless indicated otherwise in a credit line to the material. If material is not included in the article's Creative Commons licence and your intended use is not permitted by statutory regulation or exceeds the permitted use, you will need to obtain permission directly from the copyright holder. To view a copy of this licence, visit http:// creativecommons.org/licenses/by-nc/4.0/.

\section{REFERENCES}

1. Noda S, Krueger JG, Guttman-Yassky E. The translational revolution and use of biologics in patients with inflammatory skin diseases. J Allergy Clin Immunol. 2015;135(2):324-36.

2. Sawyer LM, Malottki K, Sabry-Grant C, Yasmeen N, Wright E, Sohrt A, et al. Assessing the relative efficacy of interleukin-17 and interleukin-23 targeted treatments for moderate-to-severe plaque psoriasis: a systematic review and network meta-analysis of PASI response. PLoS ONE. 2019;14(8):e0220868.

3. Armstrong AW, Puig L, Joshi A, Skup M, Williams $\mathrm{D}, \mathrm{Li} \mathrm{J}$, et al. Comparison of biologics and oral treatments for plaque psoriasis: a meta-analysis. JAMA Dermatol. 2020;156(3):258-69.
4. Armstrong AW, Siegel MP, Bagel J, Boh EE, Buell M, Cooper KD, et al. From the Medical Board of the National Psoriasis Foundation: treatment targets for plaque psoriasis. J Am Acad Dermatol. 2017;76(2): 290-8.

5. Grine L, de la Brassinne M, Ghislain P-D, Hillary T, Lambert J, Segaert S, et al. A Belgian consensus on the definition of a treat-to-target outcome set in psoriasis management. J Eur Acad Dermatol Venereol. 2020;34(4):676-84.

6. Dommasch ED, Shin DB, Troxel AB, Margolis DJ, Gelfand JM. Reliability, validity, and responsiveness to change of the patient report of extent of psoriasis involvement (PREPI) for measuring body surface area affected by psoriasis. $\mathrm{Br} \mathrm{J}$ Dermatol. 2010;162(4):835-42.

7. Finlay AY, Khan GK. Dermatology Life Quality Index (DLQI)-a simple practical measure for routine clinical use. Clin Exp Dermatol. 1994;19(3):210-6.

8. Basra MKA, Fenech R, Gatt RM, Salek MS, Finlay AY. The Dermatology Life Quality Index 1994-2007: a comprehensive review of validation data and clinical results. Br J Dermatol. 2008;159(5):997-1035.

9. Murer C, Sgier D, Mettler SK, Guillet C, Maul J-T, Djamei $V$, et al. Gender differences in psoriasis: a Swiss online psoriasis survey. Arch Dermatol Res. 2021;313(2):89-94.

10. Mabuchi T, Yamaoka H, Kojima T, Ikoma N, Akasaka E, Ozawa A. Psoriasis affects patient's quality of life more seriously in female than in male in Japan. Tokai J Exp Clin Med. 2012;37(3):84-8.

11. Schmid Y, Navarini A, Thomas ZRM, Pfleiderer B, Krähenbühl S, Mueller SM. Sex differences in the pharmacology of itch therapies-a narrative review. Curr Opin Pharmacol. 2019;46:122-42.

12. Stumpf A, Burgmer M, Schneider G, Heuft G, Schmelz M, Phan NQ et al. Sex differences in itch perception and modulation by distraction-an FMRI pilot study in healthy volunteers. PLoS ONE. 2013;8(11): e79123.

13. Sunar I, Ataman S, Nas K, Kilic E, Sargin B, Kasman SA, et al. Enthesitis and its relationship with disease activity, functional status, and quality of life in psoriatic arthritis: a multi-center study. Rheumatol Int. 2020;40(2):283-94.

14. Tillett W, Merola JF, Thaçi D, Holdsworth E, Booth $\mathrm{N}$, Lobosco LS, et al. Disease characteristics and the burden of joint and skin involvement amongst people with psoriatic arthritis: a population survey. Rheumatol Ther. 2020;7(3):617-37. 